to individual body weight, a standard reduction being made for eash age group. This was done to facilitate the work of the ward staff by reducing the number of variations of dosage to the smallest possible.

For an adult with miliary disease without meningitis a four-months intramuscular course of $2 \mathrm{~g}$. streptomycin daily was given. This was followed by a rest period of one month and a second course of intramuscular streptomycin for one month. P.A.S. was usually given throughout the stay in hospital.

In July, 1950, dihydrostreptomycin replaced streptomycin in the hospital.

Analysis of the 34 Cases Treated

\begin{tabular}{|c|c|c|c|}
\hline & & Death & Recovery \\
\hline $\begin{array}{c}\text { Tuberculous } \\
\text { meningitis }\end{array}$ & $\begin{array}{l}\text { Treated with streptomycin } \\
\text { Treated with dihydrostrepto- } \\
\text { mycin }\end{array}$ & $\begin{array}{l}3 \\
5\end{array}$ & $\begin{array}{r}14 \\
8\end{array}$ \\
\hline $\begin{array}{l}\text { Miliary } \\
\text { tuberculosis }\end{array}$ & $\begin{array}{l}\text { Treated with streptomycin } \\
\text { Treated with dihydrostrepto- } \\
\text { mycin }\end{array}$ & - & $\begin{array}{l}3 \\
1\end{array}$ \\
\hline
\end{tabular}

All the recovered cases treated with streptomycin have now been discharged, except two who are still in hospital simply because home conditions are unsuitable. All these cases have been carefully followed up to the present and every patient can hear a forced whisper at 12 feet without any difficulty. It may be stated that the services of an otologist have not been available, and a scientific assessment of hearing acuity has therefore not been possible.

\section{Cases of Deafness}

Of the cases treated with dihydrostreptomycin, there have been four in whom marked impairment of hearing has occurred either during treatment or soon after the completion of treatment.

Case 1.-A girl aged 17. She responded to treatment slowly, and a positive culture of tubercle bacilli was obtained four months after the beginning of treatment. At about the fifth month of treatment she became totally deaf within 14 days. No evidence of other cranial nerve involvement of any kind has ever been obtained. She now appears well, though she continues on treatment. She remains totally deaf.

Case 2.-A girl aged 6 years. She made an uninterrupted recovery from her meningitis without incident. During the second month of her second course of treatment with dihydrostreptomycin she became totally deaf within four days.

Case 3.-A girl aged 8 years. She made an uninterrupted recovery without incident and was first noted to be partially deaf one month after discharge from hospital at her reexamination.

Case 4.-A boy aged 8 years. He also made an uninterrupted recovery, but was first noted to be partially deaf at re-examination one month after discharge from hospital.

\section{The degree of deafness in ah four cases is now gross.} It is a nerve deafness. The loss of hearing in the first two cases was extremely rapid. In the second two cases it seems likely that it has been extremely slow. We now feel that the impairment of hearing probably began during treatment, but that the degree of impairment remained so slight that it was not detected by our crude tests until one month after discharge. This suggests that, once the auditory nerve has been damaged by the drug, progressive impairment of hearing may occur after all dihydrostreptomycin therapy has ceased.

Case $1 \mathrm{did}$ not respond satisfactorily to treatment, and it was at first felt that her deafness might be attributable to the meningeal process. However, the response to treatment in the other three cases was highly satisf $\therefore$ ctory. In none of these four cases has there ever besn any evidence of paresis of other cranial nerves.

Case 3 has recently been seen by an otologist, who states that a gross degree of nerve deafness is present, but that this could result from the meningeal process. However, it is striking that among 14 recovered cases treated with streptomycin there has been no case of deafness of any degree. Also, in three of the cases in which deafness has occurred after treatment with dihydrostreptomycin the impairment of hearing has appeared late in the course of treatment or after treatment was completed, and it seems unlikely that the meningeal process can therefore be blamed. Only one case of miliary tuberculosis has been treated with dihydrostreptomycin, and without evidence of impairment of hearing.

The evidence therefore strongly suggests that the deafness has been caused directly by the dihydrostreptomycin. There appear to be no grounds for continuing to treat cases of tuberculous meningitis with dihydrostreptomycin rather than streptomycin.

$$
\begin{aligned}
& \text { R. W. BIAGI, M.B., Ch.B., } \\
& \text { First Assistant Physician, } \\
& \text { East Fortune Hospital, Drem, }
\end{aligned}
$$
North Berwick.

\section{Case of Coma Associated with Ketonuria in a Young Adult}

The following case seems to be unusual enough to merit recording.

\section{Case Report}

A male student, aged 22, at a teachers' training college was admitted to hospital on January 16, 1951, as an emergency in a state of semi-coma. Thirty-six hours previously he had been taken ill, with colicky abdominal pains, had vomited twice, and subsequently had felt better. He slept well that night. Next morning he became stuporous and was difficult to rouse. The colicky abdominal pains returned. He had had no bowel action for two days.

When seen after admission he was lying in a comatose condition on his side with his knees drawn up. There was marked air hunger, and his breath smelt strongly of acetone bodies. His temperature was $98.4^{\circ} \mathrm{F}$. $\left(36.9^{\circ} \mathrm{C}\right.$.), pulse 70 , and respirations 22 . He could be roused, but his cerebration was slow, and he answered only in monosyllables and at once. relapsed into coma. His tongue was coated and dry; his colon was loaded. His urine gave strongly positive reactions. to the ferric-chloride and Rothera tests, but no albumin or sugar was present. His other systems revealed no abnormality. His appearance was that of a diabetic coma, but his. blood sugar was $90 \mathrm{mg}$. per $100 \mathrm{ml}$.

With general treatment he fully recovered in 48 hours and was then able to give a proper history. Three days before admission there had been a very fatty joint of beef for lunch: most of his friends had left the fat on their plates, and he had collected and eaten it all, as " he did not like waste."

It is to be presumed that this large amount of .fat, to. which he was unaccustomed, produced the ketosis. $\mathrm{He}$ stated that he was said to have suffered from acidosis as a. small boy.

C. B. S. Fuller, M.D., M.R.C.P. 